\title{
Association between GSTM1 and CYP1A1 polymorphisms and survival in oral cancer patients
}

\author{
Deepika Shukla ${ }^{a}$, Alka Dinesh Kale ${ }^{b}$, Seema Hallikerimath', Venkatakanthaiah Yerramalla ${ }^{d}$, Vivekanandhan Subbiah ${ }^{d}$, \\ Shashwat Mishra ${ }^{\mathrm{e}}$
}

\begin{abstract}
Aims. Cancer patient's inherited genotype may influence his or her survival, but evidence for the role of these genetic differences in oral cancer survival has not yet been explored.

Methods. The authors evaluated polymorphisms in the GSTM1 and CYP1A1 genes for associations with overall survival in 100 oral squamous cell carcinoma (OSCC) treated patients and 100 controls who were followed up for survival within 2 years of the date of completion of their treatment. Overall survival was evaluated in Kaplan-Meier survival functions and Cox proportional hazards models.
\end{abstract}

Results. After adjustment for stage and histology, GSTM1 null genotype was associated with shorter survival among OSCC patients, compared with GSTM1 present genotype. There was no association between CYP1A1 C genotype and survival in the overall study population.

Conclusion. The study indicated a potential role for GSTM1 polymorphism in predicting the clinical outcomes of treated oral carcinoma patients.

Key words: glutathione S transferase, cytochrome P450, polymorphism, oral squamous cell carcinoma, survival

Received: November 14, 2012; Accepted: April 16, 2013; Available online: May 3, 2013

http://dx.doi.org/10.5507/bp.2013.028

${ }^{a}$ Department of Oral Pathology and Microbiology, Faculty of Dentistry, Jamia Millia Islamia, Delhi, India

${ }^{b} K L E$ VK Institute of Dental Sciences and Hospital, Belgaum, Karnataka, India

'Department of Oral Pathology and Microbiology, KLE VK Institute of Dental Sciences and Hospital, Belgaum, Karnataka

${ }^{d}$ Neurobiochemistry, Neurosciences Centre, All India Institute of Medical Sciences, New Delhi

${ }^{e}$ Department of Neurosurgery, Ram Manohar Lohia Institte of Medical Sciences, Lucknow

Corresponding author:Deepika Shukla, e-mail:deepika_shukla06@yahoo.com

\section{INTRODUCTION}

Oral squamous cell carcinoma (OSCC) is the most common cancer in males in India and is the third most common cancer in Indian females ${ }^{1}$. The overall survival has not changed in recent years, despite extensive research on the biological and molecular features of OSCC. Drug metabolizing enzymes (DME) are responsible for the metabolism of many of the exogenous chemicals that are toxic and carcinogenic. These include phase I enzymes (cytochrome P450 (CYP) enzymes) which helps in bioactivation of carcinogens and phase II enzymes (glutathione S-transferase (GST)) which play role in detoxification of electrophilic compounds formed by the phase I enzymes. Hence, the toxic effect of exposure, absorption and detoxification of carcinogens depends on a delicate balance between the phase I and phase II enzymes ${ }^{2}$.

Despite the fact that various factors determine the efficacy of cancer treatment, systemic drug levels and tissue exposure to drug metabolites is determined by genetic differences in drug metabolizing enzyme activity of an individual ${ }^{3,4}$. CYP1A1 is known to be present in many epithelial tissues and activates tobacco procarcinogens like poly aromatic hydrocarbons and aromatic amines into their carcinogenic forms. The CYP1A1 MspI polymorphism has been associated with higher risk of tobacco-related cancers, such as oral and lung cancers ${ }^{5}$. Preliminary studies indicate that CYP1A1 is also involved in the metabolism of 5-fluorouracil, used routinely in treatment of oral cancer ${ }^{6}$.

The GST family detoxifies carcinogens, reactive oxygen species and lipid peroxidation products, yielding excretable hydrophilic metabolites ${ }^{7}$. Lack of these enzymes may potentially increase susceptibility to various cancers because of a decreased ability to detoxify carcinogen $\mathbf{s}^{5,8}$. Several chemotherapeutic drugs and their metabolites undergo the glutathione-dependent detoxification catalyzed by GST enzymes ${ }^{9,10}$. Polymorphisms of certain GST enzymes may alter the metabolism of chemotherapeutic drugs and modify the effectiveness of therapy, thus can predict differences in outcomes of treatment for cancers of various sites like breast cancer ${ }^{11-13}$, leukemias ${ }^{14-16}$ and colorectal cancer $^{17}$. GST polymorphisms may thus influence survival in cancer treated patients. Two hypothetical reasons were suggested for GST polymorphisms and survival: (a) several chemotherapy agents are substrates for glutathione conjugation catalyzed by GST enzymes ${ }^{9,16,18-21}$, as are cellular by-products of reactive oxygen damage ${ }^{22,23}$, therefore, patients may differ in response to chemo and radiation therapy depending on GST activity; and (b) susceptible GST genotypes are associated with characteristic patterns of somatic changes in tumor tissue (e.g. p53 or K-ras mutations) (ref. ${ }^{2427}$ ). If patients who have genotypes with low GST enzyme activity are expected to 
have certain somatic changes, and if the somatic changes correspond to more aggressive tumor phenotypes ${ }^{28}$, GST genotype may show association with survival differences. Various studies have reported the relation of GST polymorphisms and survival of lung cancer patients, with conflicting results ${ }^{29-32}$. Goto et al. ${ }^{33}$ reported that lung cancer patients with GSTM1 null genotype had shorter survival than patients with GSTM1 present genotype. Thus, there are probable mechanisms through which inherited GSTM1 genotype of a cancer patient may influence his or her survival ${ }^{34}$, but evidence for a role of these genetic differences in OSCC survival is not yet explored. To the best of our knowledge, there have been few studies that have examined the impact of CYP1A1 and GSTM1 polymorphism on host susceptibility to oral cancer ${ }^{5,35,36}$ but ours is the first study examining these polymorphisms as a determinant for survival in OSCC treated patients. Associations between drug metabolizing enzyme polymorphisms and patient prognosis could contribute to identifying individual differences in their potential to benefit from particular types of therapy.

\section{MATERIALS AND METHODS}

\section{Selection of cases and controls}

For the present study histopathologically confirmed 100 post treatment cases of OSCC and 100 control subjects were selected. Eligible patients to be included in the post treatment group were identified from the Karnataka Cancer Therapy And Research Institute, Padmashree Dr. R.B. Patil Cancer Hospital, Navanagar, Hubli, and obtained information on pathologic and clinical variables. Institutional review board and ethical committee approval was obtained prior to the start of the study. The Padmashree Dr. R.B. Patil Cancer Hospital actively conducts annual follow-up for each patient, and maintains information on the date of last contact, vital status, and recurrence status. Patients had been followed up for survival within 2 years of the date of completion of their treatment and were queried for this study. Informed consent was taken from all participants. Information regarding tobacco habit, stage at diagnosis, tumor site, histology and type of therapy were obtained. Eligibility criteria included histopathological diagnosis of, primary well differentiated squamous cell carcinoma and treated with surgical resection leaving negative margins followed by chemotherapy and radiation therapy. The majority of patients who received chemotherapy were treated with cysplatin based chemotherapy. All cases were patients with cancers of the oral cavity, i.e., buccal mucosa, alveolus, palate and tongue.

Controls enrolled in this study were matched for age, gender and tobacco habits. Control subjects included patients seen in the KLE VK Institute of Dental Sciences, Belgaum with conditions requiring dental treatment. The blood samples were subjected for genotype analysis.

\section{Genotyping}

Five milliliters of venous blood were collected from all study subjects in vacutainer tubes containing EDTA us- ing aseptic measures. The blood was stored at $-20{ }^{\circ} \mathrm{C}$ and transported in ice to the laboratory. DNA was extracted from peripheral blood lymphocytes by standard RNase and proteinase $\mathrm{K}$ treatment and phenol-chloroform extraction. DNA samples were stored at $-20{ }^{\circ} \mathrm{C}$ until further reactions. DNA samples were evaluated for quantity by spectrophotometry (by NanoDrop ND-1000 spectrophotometer) and quality by a $1 \%$ agarose gel run. Polymerase chain reaction (PCR) and restriction fragment length polymorphism was performed using DNA samples to determine the polymorphic genotypes at CYP1A1 and GSTM1 loci. The reaction mixtures underwent the following incubations in Applied Biosystems 2720 thermal cycler: 1 cycle of $96{ }^{\circ} \mathrm{C}$ for $30 \mathrm{~s}, 30$ cycles of $94{ }^{\circ} \mathrm{C}$ for 30 $\mathrm{s}, 56{ }^{\circ} \mathrm{C}$ for $40 \mathrm{~s}$, and $72{ }^{\circ} \mathrm{C}$ for $30 \mathrm{~s}$, followed by a final cycle of $7 \mathrm{~min}$ at $72{ }^{\circ} \mathrm{C}$. Samples were electrophoresed on $2 \%$ native polyacrylamide gels, stained with ethidium bromide and examined over UV light (UV Transilluminator).

Genotypes were analyzed using PCR-based methods as described below.

CYP1A1: The CYP1A1 mutation found in the 3-flanking region was detected by PCR and RFLP analysis using the MspI restriction enzyme ${ }^{37}$. The DNA fragment was amplified using the following primers: 5'-CAGTGAAGA-GGT-GTA-GCC-GCT-3' and 5'-TAG-GAGTCT-TGTCTC-ATG-CCT-3'. After amplification, the PCR product was subjected to restriction digestion using MspI. The products were then separated by agarose gel ( $2 \%$ gel) electrophoresis. The CYP1A1 polymorphisms were classified as homozygous for m1/m1 (CYP1A1 A genotype which produced a 340-bp band), heterozygous for $\mathrm{m} 1 /$ m2 (CYP1A1 B genotype which produced 340, 200 and 140-bp bands), or homozygous for $\mathrm{m} 2 / \mathrm{m} 2$ (CYP1A1 C genotype which produced 200 and 140-bp bands) alleles.

GSTM1: The GSTM1 genotype was detected after PCR amplification using primers for the GSTM1 gene ${ }^{38}$ and the globin gene. The GSTM1 primers were 5'-CTGCCC-TAC-TTGATT-GAT-GGG-3' and 5'-CTG-GAT-TGTAGC-AGA-TCATGC-3'. The wild-type samples produced a band at $300 \mathrm{bp}$. In the variant samples, the GSTM1 gene was absent (GSTM1 null), and no band was observed.

Globin gene: A portion of the globin gene was amplified as a positive control, producing a 200-bp fragment. The following primers were used: 5'-GAA-GAG-CCAAGG-ACA-GGTAC- 3'and 5'-GGT-GTC-TGT-TTG-AGGTTG-CT-3'.

\section{Statistical analysis:}

Statistical analysis was performed using the SPSS software (version 16). Survival was calculated for each participant of post treated OSCC patient from the date of diagnosis until the date of death or the date of last followup contact. Initial analyses included the assessment of patient and tumor characteristics by GSTM1 and CYP1A1 genotypes, using chi-square analysis. Survival estimates were based on the Kaplan-Meier survival function, with statistical significance assessed using the log-rank test. Hazard ratios (HRs) and their 95\% confidence intervals (95\% CI) were calculated from a multivariate Cox proportional hazards model,with adjustment for categories 
of stage at diagnosis as strata in the model and other prognostic characteristics like age, site, gender and histology as covariates. Overall relative risk of death associated with GSTM1 and CYP1A1 were estimated from this cox model, with adjusted potential cofounding variables.

\section{RESULTS}

A total of 100 post treated OSCC cases and 100 controls were entered into the study, of which $73.9 \%$ were males (Table 1). The mean age of the control group (49.9 years; range, 18-79) was identical to that of the case groups (51years; range, 32-70; Table 1). Older patients (age >50 years) were not significantly associated with poorer survival compared with younger patients. Maximum cases (46\%) in study groups were from buccal mucosa.

Tobacco history before OSCC treatment revealed that most (78\%) were chewers. To evaluate gene-tobacco interactions, the prevalence of CYP1A1 and GSTM1 were stratified by tobacco history. As expected, OSCC cases had a significantly higher frequency of tobacco consump-

Table 1. Distribution of study subjects according to CYP1A1 and GSTM1 genotypes according to different characteristics.

\begin{tabular}{|c|c|c|c|c|c|c|c|c|c|c|c|c|}
\hline \multirow{2}{*}{ Genotype } & \multirow{2}{*}{ 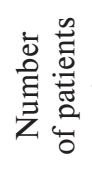 } & \multicolumn{2}{|c|}{ Gender } & \multicolumn{2}{|c|}{$\begin{array}{l}\text { Age at diagnosis } \\
\text { (years) }\end{array}$} & \multicolumn{3}{|c|}{ Stage at diagnosis } & \multicolumn{4}{|c|}{ Site } \\
\hline & & Male & Female & $<=50$ & $>50$ & $\begin{array}{l}\text { Stage } \\
\text { II }\end{array}$ & $\begin{array}{l}\text { Stage } \\
\text { III }\end{array}$ & $\begin{array}{l}\text { Stage } \\
\text { IV }\end{array}$ & $\begin{array}{l}\text { Buccal } \\
\text { mucosa }\end{array}$ & Tongue & Alveolus & Palate \\
\hline \multicolumn{13}{|l|}{ CYP1A1 } \\
\hline $\mathrm{A}(\mathrm{m} 1 \mathrm{~m} 1)$ & 60 & 42 & 18 & 38 & 22 & 6 & 22 & 32 & 36 & 4 & 10 & 10 \\
\hline $\mathrm{B}(\mathrm{m} 1 \mathrm{~m} 2)$ & 30 & 16 & 14 & 12 & 18 & 0 & 4 & 26 & 6 & 2 & 18 & 4 \\
\hline $\mathrm{C}(\mathrm{m} 2 \mathrm{~m} 2)$ & 10 & 6 & 4 & 6 & 4 & 2 & 2 & 6 & 4 & 0 & 4 & 2 \\
\hline Chi-square & & \multicolumn{2}{|c|}{1.2440} & \multicolumn{2}{|c|}{0.9720} & \multicolumn{3}{|c|}{4.8610} & \multicolumn{4}{|c|}{4.4460} \\
\hline$P$-value & & \multicolumn{2}{|c|}{0.5368} & \multicolumn{2}{|c|}{0.6150} & \multicolumn{3}{|c|}{0.0880} & \multicolumn{4}{|c|}{0.2170} \\
\hline GSTM1present & 56 & 40 & 16 & 30 & 26 & 6 & 24 & 26 & 28 & 6 & 14 & 8 \\
\hline GSTM1null & 38 & 20 & 18 & 22 & 16 & 2 & 2 & 34 & 14 & 0 & 18 & 6 \\
\hline Chi-square & & \multicolumn{2}{|c|}{1.7320} & \multicolumn{2}{|c|}{0.0860} & \multicolumn{3}{|c|}{9.4650} & \multicolumn{4}{|c|}{4.0101} \\
\hline$P$-value & & \multicolumn{2}{|c|}{0.1881} & \multicolumn{2}{|c|}{0.7701} & \multicolumn{3}{|c|}{$0.0090 *$} & \multicolumn{4}{|c|}{0.2601} \\
\hline
\end{tabular}

* Significant at $5 \%$ level of significance $(P<0.05)$.

Results were not interpretable for 6 subjects for GSTM1 genotype.

Table 2. CYP1A1 and GSTM1 genotypes with respect to tobacco consumption.

\begin{tabular}{cccccc}
\hline Group & Genotype & No. of patients & $\begin{array}{c}\text { Tobacco mean } \\
\text { duration }\end{array}$ & Mean Frequency & $\begin{array}{c}\text { Lifetime } \\
\text { exposure }\end{array}$ \\
\hline Post treatment group & CYP1A1 & & & & \\
& A(m1m1) & 60 & $21.67 \pm 9.29$ & $11.03 \pm 5.51$ & 243.6 \\
& B(m1m2) & 30 & $20.47 \pm 10.23$ & $10.00 \pm 4.12$ & 229.6 \\
& C(m2m2) & 10 & $15.80 \pm 10.90$ & $7.80 \pm 3.19$ & 127.1 \\
& GSTM1present & 56 & $21.68 \pm 9.49$ & $10.57 \pm 5.20$ & 231.2 \\
Total & GSTM1nul & 38 & $19.95 \pm 10.04$ & $10.53 \pm 5.00$ & 237.5 \\
Healthy control & & 100 & $20.72 \pm 9.69$ & $10.40 \pm 4.96$ & 227.7 \\
& CYP1A1 & & & & 33.2 \\
& A(m1m1) & 48 & $5.5 \pm 2.77$ & $6.25 \pm 2.38$ & 27.9 \\
T(m1m2) & 46 & $6.29 \pm 5.75$ & $5.04 \pm 2.49$ & 33.2 \\
& C(m2m2) & 6 & $5.50 \pm 0.71$ & $6.00 \pm 6.00$ & 29 \\
& GSTM1present & 78 & $5.90 \pm 4.83$ & $5.42 \pm 2.41$ & 40.5 \\
\hline
\end{tabular}

Post treatment cases had a significantly higher frequency and duration of tobacco consumption $(P<0.0001)$ as compared to controls. Further, on comparing genotype with nature and lifetime exposure of tobacco consumption, odds ratio was not found to be significant. Results were not interpretable for 6 subjects for GSTM1 genotype for post treatment group. 
tion $(P<0.00001)$ compared to controls. Similarly oral cancer patients had significantly higher duration of tobacco consumption than controls $(P<0.0001$; Table 2$)$. Lifetime exposure was calculated among all tobacco users for both cases and controls (Lifetime exposure $=$ Frequency of chewing events per day $\mathrm{X}$ duration in years or number of cigarettes/10 X duration in years). Lifetime exposure for tobacco consumption revealed that oral cancer patients were maximally exposed compared to controls. Further, on comparing genotype with nature and lifetime exposure of tobacco consumption, odds ratio was not found to be significant.

A total of 30 deaths were recorded during the followup period with cancer as the cause of death for 19, other causes known for 4 and unknown for 7. Follow-up among patients who were alive at the end of observation was 7-19 months. Follow-up was essentially complete to 19 months, with only 4 living subjects censored (lost to follow-up). 6 cases were recorded with recurrence of oral cancer who were alive and getting treated for the same. When genotype was compared with age group and site of primary lesion, CYP1A1 and GSTM1 genotype were not associated with age and site $(P>0.05)$. Most cases of deaths in the post treatment group had primary lesion in alveolus (60\%) followed by buccal mucosa (26.7\%, Table 3$)$. Most cases of deaths in the post treatment group were seen in stage IV (100\%).

The distributions of CYP1A1 and GSTM1 genotypes according to patient characteristics are shown in Table 1. The Kaplan-Meier survival functions for overall survival by GSTM1 and CYP1A1 genotypes are presented

Table 3. Analysis with respect of sites with deaths among post treated oral squamous cell carcinoma patients.

\begin{tabular}{lcc}
\hline Site & No. of patients & No. of deaths \\
\hline Buccal mucosa, $\mathrm{n}[\%]$ & $46[46]$ & $8[26.7]$ \\
Tongue, $\mathrm{n}[\%]$ & $6[6]$ & $0[0]$ \\
Alveolus, $\mathrm{n}[\%]$ & $32[32]$ & $\mathbf{1 8 [ 6 0 ]}$ \\
Palate, $\mathrm{n}[\%]$ & $16[16]$ & $4[13.3]$ \\
Total & 100 & 30 \\
\hline
\end{tabular}

in Figures 1, 2 and 3. The Relative Risk (RR) of death associated with GSTM1, and CYP1A1 genotypes are shown in Table 4.

\section{GSTM1 polymorphisms}

Of the 100 subjects genotyped for GSTM1, the results were not interpretable for 6 subjects who showed uninformative genotyping, so the GSTM1 analysis is based on 94 subjects. None of the missed subjects reported reccurences. An association between GSTM1 null genotype and increased risk of OSCC recurrence was present in this study population; there was also an association between GSTM1null genotypes with stage IV cancers. On the basis of the difference in the survival curves by GSTM1 genotype (Fig. 1 and 3) and on the log-rank test (Table 4), there was an indication that GSTM1 null individuals had shorter survival than GSTM1present subjects. The Kaplan-Meier estimates overall survival for GSTM1 present subjects and for GSTM1 null subjects. GSTM1 is also associated with stage at diagnosis $(P<0.05)$. After adjustment for stage and histology, which were strong predictors of survival, GSTM1null genotype was associated with shorter survival among OSCC patients, with an adjusted death RR of 1.20, compared with GSTM1 present genotype. Additional adjustment for age, tumor site or history of a previous primary malignancy had essentially no effect on the Relative Risk. When the genotype was compared between post treatment group and control group, GSTM1 null genotype showed significant association with patients who died due to reccurence in the post treatment group.

\section{CYP1A1 polymorphisms}

Genotypes for CYP1A1were available for all 100 subjects. When we tested the relationship between CYP1A1 genotype polymorphism in all OSCC patients and the survival, no significant difference was observed between Kaplan-Meier survival curves.

\section{GSTM1 and CYP1A1 polymorphisms}

We conducted further analyses to explore whether the combination of GSTM1 and CYP1A1 is associated with

Table 4. Relative Risk for survival rates in CYP1A1 and GSTM1 among post treated oral squamous cell carcinoma patients.

\begin{tabular}{lccccc}
\hline Genotype & No. of Patients & No. of Deaths & Relative risk (RR) & 95\% Confidence & $P$-value \\
& & & & Interval & $0.0259^{*}$ \\
\hline GSTM1 present & 56 & 4 & 1.01 & $0.61-1.67$ & 0.9908 \\
GSTM1 null & 38 & 26 & $\mathbf{1 . 2 0}$ & $0.52-2.76$ & \\
\hline CYP1A1 & 60 & 10 & & & $0.38-2.13$ \\
A(m1m1) & 30 & 18 & 0.90 & $0.29-2.81$ & $0.05-4.16$ \\
B(m1m2) & 10 & 2 & 0.47 & \\
C(m2m2) & & & &
\end{tabular}




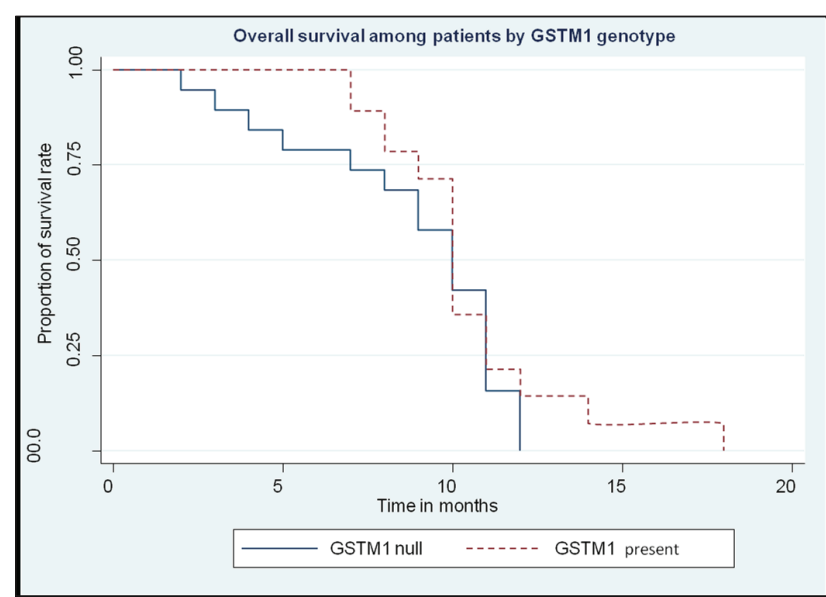

Fig. 1. Kaplan-Meier function for overall survival among patients treated for oral squamous cell carcinoma (SCC), by GSTM1 genotype.

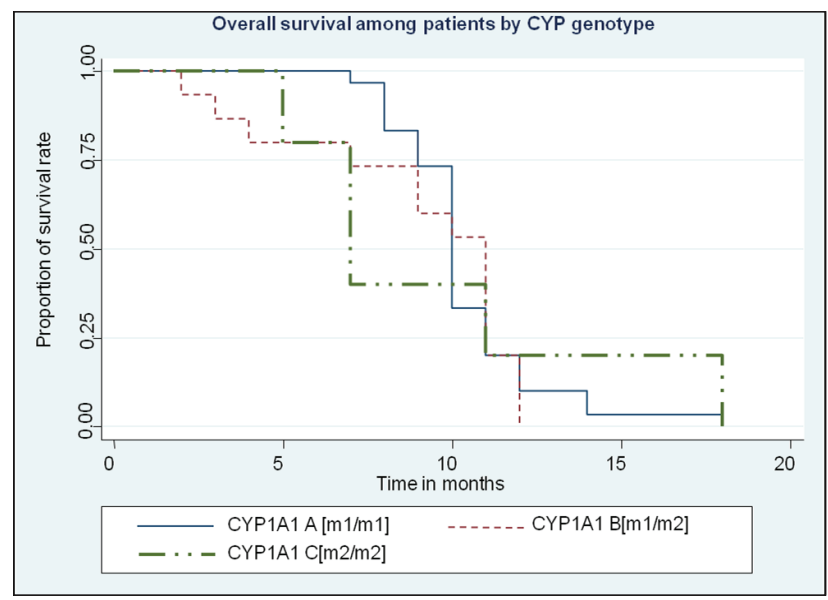

Fig. 2. Kaplan-Meier function for overall survival among patients treated for OSCC, by CYP1A1 genotype.

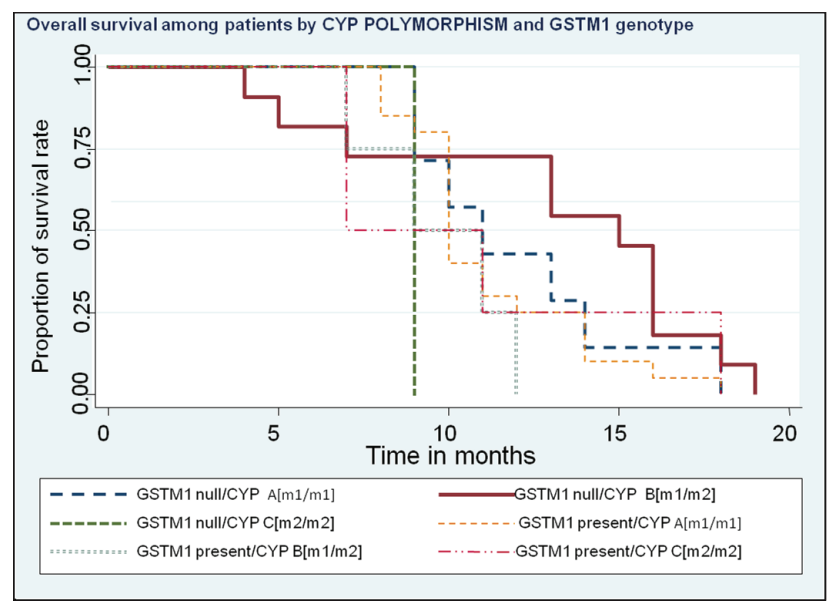

Fig. 3. Kaplan-Meier function for overall survival among patients treated for OSCC, by combined GSTM1 and CYP1A1 genotype. survival. Patients who had both CYP1A1 B (m1m2) genotype and GSTM1 null genotype died the most compared to the other genotypes, but this did not reach statistical significance (data not shown).

\section{DISCUSSION}

Our analysis of the common polymorphisms of two genes namely CYP1A1 and GSTM1 in patients who were treated for oral squamous cell carcinoma demonstrates that subjects with the GSTM1 null genotype had more deaths than patients with GSTM1 present genotype. The relative risk of death associated with GSTM1 null genotype, adjusted for site, stage at diagnosis and histology, was 1.20 (95\% CI 0.52-2.76).

The association of GSTM1 genotype with survival of cancer treated patients can be explained by the differences in detoxification of treatment agents or differences in carcinogen damage to DNA. Thus patients with GSTM1 null genotypes will have higher effective dose of chemotherapy leading to increased reactive oxidant damage to tumor tissue. Hence in GSTM1 null individuals therapy might be more effective, indicating longer survival as reported for GSTM1 null breast cancer patients ${ }^{11,13}$.

In the present study of OSCC, the direction of the association was the reverse. Patients with reduced ability for GST-mediated detoxification showed shorter survival probably due to more severe therapy-related toxicity. This was consistent with a previous study in which GSTT1 null leukemia patients treated with high-dose therapy reported an increased number of deaths accredited to therapy-related toxicity ${ }^{16}$. The shorter survival in association with GSTM1 null genotype that was observed in the present study is also consistent with Goto et al. ${ }^{33}$ who suggested that smokers with GSTM1 null genotype had more tendency to develop cancers with mutations of $\mathrm{p} 53$, K-ras, and/or genes that are known to play a role in tumor development, growth and metastasis. Thus GSTM1 null patients would be likely to have more aggressive tumor biology and shorter survival, even after taking into account stage at diagnosis, as was observed in the present study.

This hypothesis is further supported by a study which reported that patients with breast carcinoma and inheritance of double null deletion of GSTM1 may have an increased risk of a secondary chemotherapy-induced hematologic neoplasm ${ }^{39}$. Interestingly, Crump et a ${ }^{40}$ found a slightly higher prevalence of GSTM1 gene deletions in patients with secondary acute myeloblastic leukemia (AML) compared to patients with de novo AML or controls; however, their result was not statistically significant.

Vaury et al. hypothesized that CYP1A1 genoype and GSTM1 null interactions result in a greater-than-additive risk for DNA damage and cancer ${ }^{41}$ Moreover, deletion of GSTM1 is associated with strong inducibility of CYP1A1 gene transcription by 2,4,7,8-tetrachlorodibenzo-para-dioxin, suggesting that this genotype combination predisposes to an increased risk for tobacco-associated DNA damage. However, in our study, no significant association was seen in the combined genotype of GSTM1 and CYP1A1 with 
survival of patients. Although studies have shown association of CYP1A1 with incidence of oral cancer ${ }^{42}$, no association was seen between this genotype and survival of OSCC in the present study population.

In the present study, most patients (78\%) were tobacco chewers suggesting that the tobacco chewing habit with or without BQ prevalent in India also contributes to increased risk of oral cancer, due to additional exposure to alkaloids and polyphenols from the areca nut whereas in western countries, cigarette smoking and heavy alcohol consumption are the main risk factors ${ }^{43}$. In our study smokers constituted a low percentage of subjects, and therefore the risk due to smoking could not be seen. Next, estimating the cumulative tobacco dose for patients exhibiting MspI genotypes of CYP1A1, it was found that SCC patients with genotype $\mathrm{C}$ had a relatively lower dose than patients with genotypes A and B. Also, the estimated tobacco dose for the patients with GSTM1 null was less than that for GSTM1present patients. It was suspected that the genotypes C and GSTM1 null play an important role in individual differences in susceptibility to oral SCC, especially to the lowest tobacco dose level. The results of this study revealed that genetically predisposed BQ/ tobacco chewers are much more susceptible to environmental and life-style risk factors.

Another interesting finding in the study was that though most cases were from the buccal mucosa (46\%), most deaths in the post treatment group had the primary lesion in alveolus ( $60 \%$ ) followed by buccal mucosa (26.7\%). This is consistent with Tanimoto et al. who also reported that buccal mucosa and upper gingiva appear to be the most susceptible tissues for OSCC in patients carrying the combination of homozygous CYP1A1 (m1/ m1) and GSTM1 (ref. ${ }^{36}$ ). Further, we also noted that most cases of deaths the in post treatment group were seen in stage IV (100\%).

\section{CONCLUSION}

The underlying mechanism for the GSTM1-survival association should be further investigated. If the mechanism for the GSTM1-survival association is through the presence of p53 and/or K-ras mutations, as seems plausible, then the results of the present study may serve to reinforce the importance of considering GSTM1 genotype in future studies of oral cancer survival. Hence it is concluded that the xenobiotic metabolizing enzymes reported in the present study, GSTM1, significantly alter the prognosis of OSCC treated patients. The present study reinstates the complexity of the interplay between genetic factors as determinants of survival of OSCC. Knowledge of the prevalence and distribution of common genetic susceptibility factors and the ability to identify susceptible individuals or subgroups will have substantial preventive implications, in particular if more data are collected to show that people with certain "at risk" genotypes are more susceptible to recurrence after OSCC treatment.

\section{CONFLICT OF INTEREST STATEMENT}

Author's conflict of interest disclosure: The authors stated that there are no conflicts of interest regarding the publication of this article.

\section{REFERENCES}

1. Rai R, Kulkarni V, Saranath D. Genome wide instability scanning in chewing-tobacco associated oral cancer using inter simple sequence repeat PCR. Oral Oncol 2004;40:1033-9.

2. Bartsch H, Nair U, Risch A, Rojas M, Wikman H, Alexandrov K. Genetic polymorphism of CYP genes, alone or in combination, as a risk modifier of tobacco-related cancers. Cancer Epidemiol Biomarkers Prev 2000;9:3-28.

3. West WL, Knight EM, Pradhan S, Hinds TS. Interpatient variability: genetic predisposition and other genetic factors. J Clin Pharmacol 1997;37:635-48.

4. Evans WE, Relling MV. Pharmacogenomics: translating functional genomics into rational therapeutics. Science 1999;286:487-91.

5. Hashibe M, Brennan P, Strange RC, Bhisey R, Cascorbi I, Lazarus P, Oude Ophuis MB, Benhamou S, Foulkes WD, Katoh T, Coutelle C, Romkes M, Gaspari L, Taioli E, Boffetta P. Meta- and pooled analyses of GSTM1, GSTT1, GSTP1, and CYP1A1 genotypes and risk of head and neck cancer. Cancer Epidemiol Biomarkers Prev 2003;12:150917.

6. Choi YH, Bae SK, Kim SO, Lee MG. Pharmacokinetics of 5-fluorouracil in mutant Nagase analbuminemic rats: faster metabolism of 5-fluorouracil via CYP1A. Biopharm Drug Dispos 2007;28:87-95.

7. Jancova P, Anzenbacher P, Anzenbacherova E. Phase II drug metabolizing enzymes. Biomed Pap Med Fac Univ Palacky Olomouc Czech Repub;154:103-16.

8. Katoh T, Nagata N, Kuroda $\mathrm{Y}$, Itoh H, Kawahara A, Kuroki N, Ookuma R, Bell DA. Glutathione S-transferase M1 (GSTM1) and T1 (GSTT1) genetic polymorphism and susceptibility to gastric and colorectal adenocarcinoma. Carcinogenesis 1996;17:1855-9.

9. Hayes JD, Pulford DJ. The glutathione S-transferase supergene family: regulation of GST and the contribution of the isoenzymes to cancer chemoprotection and drug resistance. Crit Rev Biochem Mol Biol 1995;30:445-600.

10. Dirven HA, van Ommen B, van Bladeren PJ. Glutathione conjugation of alkylating cytostatic drugs with a nitrogen mustard group and the role of glutathione S-transferases. Chem Res Toxicol 1996;9:351-60.

11. Kelsey KT, Hankinson SE, Colditz GA, Springer K, Garcia-Closas M, Spiegelman D, Manson JE, Garland M, Stampfer MJ, Willett WC, Speizer FE, Hunter DJ. Glutathione S-transferase class mu deletion polymorphism and breast cancer: results from prevalent versus incident cases. Cancer Epidemiol Biomarkers Prev 1997;6:511-5.

12. Sweeney C, McClure GY, Fares MY, Stone A, Coles BF, Thompson PA, Korourian S, Hutchins LF, Kadlubar FF, Ambrosone CB. Association between survival after treatment for breast cancer and glutathione S-transferase P1 Ile105Val polymorphism. Cancer Res 2000;60:56214.

13. Ambrosone CB, Sweeney C, Coles BF, Thompson PA, McClure GY, Korourian S, Fares MY, Stone A, Kadlubar FF, Hutchins LF. Polymorphisms in glutathione S-transferases (GSTM1 and GSTT1) and survival after treatment for breast cancer. Cancer Res 2001;61:7130-5.

14. Stanulla M, Schrappe $M$, Brechlin AM, Zimmermann M, Welte K. Polymorphisms within glutathione S-transferase genes (GSTM1, GSTT1, GSTP1) and risk of relapse in childhood B-cell precursor acute lymphoblastic leukemia: a case-control study. Blood 2000;95:1222-8.

15. Hall AG, Autzen P, Cattan AR, Malcolm AJ, Cole M, Kernahan J, Reid MM. Expression of mu class glutathione S-transferase correlates with event-free survival in childhood acute lymphoblastic leukemia. Cancer Res 1994;54:5251-4.

16. Davies SM, Robison LL, Buckley JD, Tjoa T, Woods WG, Radloff GA, Ross JA, Perentesis JP. Glutathione S-transferase polymorphisms and outcome of chemotherapy in childhood acute myeloid leukemia. J Clin Oncol 2001;19:1279-87. 
17. Stoehlmacher J, Park DJ, Zhang W, Groshen S, Tsao-Wei DD, Yu MC, Lenz HJ. Association between glutathione S-transferase P1, T1, and M1 genetic polymorphism and survival of patients with metastatic colorectal cancer. J Natl Cancer Inst 2002;94:936-42.

18. Srivastava SK, Singhal SS, Hu X, Awasthi YC, Zimniak P, Singh SV Differential catalytic efficiency of allelic variants of human glutathione S-transferase Pi in catalyzing the glutathione conjugation of thiotepa. Arch Biochem Biophys 1999;366:89-94.

19. Dirven HA, Megens L, Oudshoorn MJ, Dingemanse MA, van Ommen $B$, van Bladeren PJ. Glutathione conjugation of the cytostatic drug ifosfamide and the role of human glutathione S-transferases. Chem Res Toxicol 1995;8:979-86.

20. Goto S, lida T, Cho S, Oka M, Kohno S, Kondo T. Overexpression of glutathione S-transferase pi enhances the adduct formation of cisplatin with glutathione in human cancer cells. Free Radic Res 1999;31:549-58.

21. Pandya U, Srivastava SK, Singhal SS, Pal A, Awasthi S, Zimniak P, Awasthi YC, Singh SV. Activity of allelic variants of Pi class human glutathione S-transferase toward chlorambucil. Biochem Biophys Res Commun 2000;278:258-62.

22. Ketterer B. Glutathione S-transferases and prevention of cellular free radical damage. Free Radic Res 1998;28:647-58.

23. Berhane K, Widersten M, Engstrom A, Kozarich JW, Mannervik B. Detoxication of base propenals and other alpha, beta-unsaturated aldehyde products of radical reactions and lipid peroxidation by human glutathione transferases. Proc Natl Acad Sci U S A 1994;91:1480 4.

24. Kawajiri K, Eguchi H, Nakachi K, Sekiya T, Yamamoto M. Association of CYP1A1 germ line polymorphisms with mutations of the p53 gene in lung cancer. Cancer Res 1996;56:72-6.

25. Ryberg D, Skaug V, Hewer A, Phillips DH, Harries LW, Wolf CR, Ogreid D, Ulvik A, Vu P, Haugen A. Genotypes of glutathione transferase M1 and $\mathrm{P} 1$ and their significance for lung DNA adduct levels and cancer risk. Carcinogenesis 1997; 18:1285-9.

26. Matsuzoe D, Hideshima T, Iwasaki A, Yoneda S, Kawahara K, Shirakusa T, Kimura A. Glutathione S-transferase mu1 null genotype is associated with K-ras gene mutation in lung adenocarcinoma among smokers. Carcinogenesis 2001;22:1327-30.

27. Curigliano G, Ferretti G, Mandala M, De Pas T, Calabro MG, Solli $P$ Noberasc C, de Braud F. GSTM1, P53 and K-ras molecular detection in resectable non-small cell lung cancer by denaturing gradient gel electrophoresis-bronchoalveolar lavage fluid analysis. Anticancer Res 2001;21:3461-9.

28. Mitsudomi T, Hamajima N, Ogawa M, Takahashi T. Prognostic significance of p53 alterations in patients with non-small cell lung cancer: a meta-analysis. Clin Cancer Res 2000;6:4055-63.

29. Sweeney C, Nazar-Stewart V, Stapleton PL, Eaton DL, Vaughan TL. Glutathione S-transferase M1, T1, and P1 polymorphisms and survival among lung cancer patients. Cancer Epidemiol Biomarkers Prev 2003; 12:527-33.
30. Yang P, Yokomizo A, Tazelaar HD, Marks RS, Lesnick TG, Miller DL, Sloan JA, Edell ES, Meyer RL, Jett J, Liu W. Genetic determinants of lung cancer short-term survival: the role of glutathione-related genes. Lung Cancer 2002;35:221-9.

31. Gonlugur U, Pinarbasi H, Gonlugur TE, Silig Y. The association between polymorphisms in glutathione S-transferase (GSTM1 and GSTT1) and lung cancer outcome. Cancer Invest 2006;24:497-501.

32. Sreeja L, Syamala V, Hariharan S, Syamala VS, Raveendran PB, Sivanandan CD, Madhavan J, Ankathil R. Glutathione S-transferase M1, T1 and P1 polymorphisms: susceptibility and outcome in lung cancer patients. J Exp Ther Oncol 2008;7:73-85.

33. Goto I, Yoneda S, Yamamoto M, Kawajiri K. Prognostic significance of germ line polymorphisms of the CYP1A1 and glutathione S-transferase genes in patients with non-small cell lung cancer. Cancer Res 1996;56:3725-30.

34. Olshan AF, Weissler MC, Watson MA, Bell DA. GSTM1, GSTT1, GSTP1, CYP1A1, and NAT1 polymorphisms, tobacco use, and the risk of head and neck cancer. Cancer Epidemiol Biomarkers Prev 2000;9:185-91.

35. Hung HC, Chuang J, Chien YC, Chern HD, Chiang CP, Kuo YS Hildesheim A, Chen CJ. Genetic polymorphisms of CYP2E1, GSTM1, and GSTT1; environmental factors and risk of oral cancer. Cancer Epidemiol Biomarkers Prev 1997;6:901-5.

36. Tanimoto $\mathrm{K}$, Hayashi $\mathrm{S}$, Yoshiga $\mathrm{K}$, Ichikawa T. Polymorphisms of the CYP1A1 and GSTM1 gene involved in oral squamous cell carcinoma in association with a cigarette dose. Oral Oncol 1999;35:191-6.

37. Kawajiri K, Watanabe J, Hayashi S. Identification of allelic variants of the human CYP1A1 gene. Methods Enzymol 1996;272:226-32.

38. Comstock KE, Sanderson BJ, Claflin G, Henner WD. GST1 gene deletion determined by polymerase chain reaction. Nucleic Acids Res 1990;18:3670.

39. Haase D, Binder C, Bunger J, Fonatsch C, Streubel B, Schnittger S, Griesinger F, Westphal G, Schoch C, Knopp A, Berkovicz D, Krieger O, Wörmann B, Hilgers R, Hallier E, Schulz T. Increased risk for therapyassociated hematologic malignancies in patients with carcinoma of the breast and combined homozygous gene deletions of glutathione transferases M1 and T1. Leuk Res 2002;26:249-54.

40. Crump C, Chen C, Appelbaum FR, Kopecky KJ, Schwartz SM, Willman $\mathrm{CL}$, Slovak ML, Weiss NS. Glutathione S-transferase theta 1 gene deletion and risk of acute myeloid leukemia. Cancer Epidemiol Biomarkers Prev 2000;9:457-60.

41. Vaury C, Laine R, Noguiez P, de Coppet P, Jaulin C, Praz F, Pompon D, Amor-Guéret M. Human glutathione $S$-transferase $M 1$ null genotype is associated with a high inducibility of cytochrome P450 1A1 gene transcription. Cancer Res 1995;55:5520-3.

42. Anantharaman D, Chaubal PM, Kannan S, Bhisey RA, Mahimkar MB Susceptibility to oral cancer by genetic polymorphisms at CYP1A1, GSTM1 and GSTT1 loci among Indians: tobacco exposure as a risk modulator. Carcinogenesis 2007;28:1455-62.

43. La Vecchia C, Tavani A, Franceschi S, Levi F, Corrao G, Negri E. Epidemiology and prevention of oral cancer. Oral Oncol 1997;33:30212. 